\title{
Endoscopic dacryocystorhinostomy for acquired nasolacrimal duct obstruction: long-term results in 91 procedures*
}

\author{
Athanasios Saratziotis ${ }^{1}$, Enzo Emanuelli², Haralampos Gouveris³ \\ Evangelia Tsironi ${ }^{4}$, Kostas Fountas ${ }^{5}$ \\ 1 Department of Otolaryngology, Head and Neck Surgery, University Hospital of Larissa, Greece \\ 2 Department of Otolaryngology and Otologic Surgery, University Hospital of Padova, Italy \\ ${ }^{3}$ Department of Otolaryngology, Head and Neck Surgery, University of Mainz Medical Center, Mainz, Germany \\ ${ }^{4}$ Department of Ophthalmology, University Hospital of Larissa, Greece \\ ${ }^{5}$ Department of Neurosurgery, University Hospital of Larissa, Greece
}

Rhinology 52: 413-418, 2014

DOl:10.4193/Rhino13.218

*Received for publication:

December 12, 2013

Accepted: May 23, 2014

\begin{abstract}
Background: The purpose of the present study was to evaluate long-term outcomes of endoscopic dacryocystorhinostomy (DCR) using a drill without the use of mucosal flaps. Ninety one procedures in eighty seven patients were reviewed. All patients showed epiphora, caused by primary or secondary nasolacrimal obstruction.
\end{abstract}

Methodology: All patients underwent preoperative evaluation (irrigation and probing of the lacrimal drainage system, fluorescein tests, computerized tomography scan of the paranasal sinuses, dacryocystography and endoscopic examination of the nasal cavity). In 19 patients further intranasal procedures were conducted simultaneously with DCR (10 FESS, 2 septoplasties, 5 functional endoscopic sinus surgery (FESS) and septoplasties, 2 septoplasties and turbinoplasties). Stents were placed intraoperatively and removed 4 to 12 weeks, postoperatively. Postoperative follow-up ranged between 12 and 24 months.

Results: Long-term success was achieved in $87 / 91$ procedures. No major complications were observed. Failure was caused by granulation tissue formation in three patients and inappropriate stent removal in one patient.

Conclusion: The success rate achieved is comparable to success rates of external DCR.

Key words: endoscopic, dacryocystorhinostomy, epiphora, nasolacrimal, drill

\section{Introduction}

Dacryocystorhinostomy (DCR), the surgical anastomosis between the nasolacrimal sac of the tear drainage system and the nose ${ }^{(1)}$, is the procedure of choice in patients with obstruction of the nasolacrimal duct and dacryocystitis, either chronic or acute.

The external procedure, first introduced by Toti ${ }^{(2)}$ in the early 1900's and modified some years later by Dupuy-Dutemps and Bourguet ${ }^{(3)}$, used to be the most popular approach for the treatment of obstructions of the nasolacrimal duct and is favoured by many ophthalmologists. The endonasal procedure, first proposed by Caldwell ${ }^{(4)}$ in the late 1800's and later modified by
West ${ }^{(5)}$ and Halle ${ }^{(6)}$, had found limited practical application due to difficulties visualizing the nasal cavity.

Since the development of the rigid endoscope and further advances in videoscopic visualization, there has been an increased interest in the intranasal techniques for DCR. The most important advantage of endoscopic DCR is the superior aesthetic result, since there is no external suturing or visible scar, as well as the additional benefit of simultaneously treating additional endonasal pathology.

In the present study, we evaluated the outcomes of endoscopic $D C R$, using a drill to create the bone window and without the use of mucosal flaps, performed over a 6-year period. Current 
literature is limited to smaller series reporting on preliminary data ${ }^{(7)}$. We present the long-term outcomes in one of the largest series in the literature.

\section{Materials and methods}

\section{Patients' data}

After approval of the Ethics Committee, a retrospective study on all patients who were referred to a tertiary academic medical centre (Department of Otology and Otolaryngology, University Hospital of Padova, Italy) for nasolacrimal obstruction between March 2003 and November 2009 was performed.

During this period, a total of 91 endoscopic dacryocystorhinostomies were performed in 87 patients, four of which were operated bilaterally simultaneously. The mean patients' age was 53.7 years (range 15-84 years) of whom 36 patients (41.38\%) were male and 51 (58.62\%) were female. Patients' demographic data are summarized in Table 1.

\section{Preoperative evaluation}

The preoperative evaluation consisted of clinical ophthalmological and endoscopic evaluation. The preoperative ophthalmological evaluation included irrigation and probing of the lacrimal drainage system and fluorescein tests (Jones I and II). The exact position of the tear drainage blockage was confirmed by the means of the Jones' tests.

Every patient underwent an endoscopic evaluation. Endoscopic evaluation of the endonasal cavities was conducted using a $2.7 \mathrm{~mm}, 30^{\circ}$ direction of view endoscope, which is used for narrow anatomical conditions or corresponding pathology. In some cases, $70^{\circ}$ endoscopes were used for specific purposes (inspection of the frontal recess, postoperative inspection of the sinus through the ostia). The information obtained about the inferior and middle turbinate and the maxillary line is of great importance. Also, it is important to examine the inferior meatus and Hasner's valve. Moreover, the degree of pneumatization of the agger nasi cell and the course of the uncinate process and especially its anterior insertion should be estimated.

The clinical examination also included a computerized tomography (CT) scan of the paranasal sinuses and, in some cases, dacryocystography. Axial and coronal images from highresolution $\mathrm{CT}$ provided precise information on the anatomy of the nasolacrimal duct. This allowed for additional detection of simultaneous endonasal pathology that cause compression of the nasolacrimal ducts. It is important to identify the anterior insertion of the uncinate process at the lacrimal sac level on an axial scan and the relationship between the lacrimal sac and the agger nasi cell on a coronal scan, as they influence the surgical management.

Additionally, cystic dilation of the distal end of the NLD, an underestimated cause of epiphora in adults, which remains undetected by the sole ophthalmologic work-up and routine nasal
Table 1. Patients' Data.

\begin{tabular}{|lccc|}
\hline & Total & Male & Female \\
\hline Patients number (\%) & 87 & $36(41.38 \%)$ & $51(58.62 \%)$ \\
\hline Age & & & \\
\hline Mean \pm SD & $53.7 \pm 16.52$ & $56.2 \pm 13.1$ & $51.9 \pm 18.5$ \\
\hline Range & $15-84$ & $28-79$ & $15-84$ \\
\hline Procedures & 91 & $37(40.66 \%)$ & $54(59.34 \%)$ \\
\hline Laterality & & & \\
\hline Left (\%) & $41(47.13 \%)$ & $22(58.33 \%)$ & $20(39.22 \%)$ \\
\hline Right (\%) & $42(48.28 \%)$ & $14(38.89 \%)$ & $28(54.90 \%)$ \\
\hline Bilateral (\%) & $4(4.59 \%)$ & $1(2,78 \%)$ & $3(5.88 \%)$ \\
\hline
\end{tabular}

SD: Standard Devation

endoscopy, is easily diagnosed on coronal imaging from a sinus CT scan and with a nasal endoscopy of the inferior meatus ${ }^{\left({ }^{8}\right)}$. All patients showed chronic epiphora. In most cases, tearing was the sole symptom. Other symptoms included swelling, pus extraction through the punctum, redness over the lacrimal sac at medial canthus and dacryocystocele. One patient suffered from acute dacryocystitis with severe tearing.

Epiphora was mainly caused by primary acquired nasolacrimal duct obstruction (62 cases, i.e. 68.13\%) and nasolacrimal sac mucoceles (14 cases, i.e. $15.38 \%)$. Chronic dacryocystitis was present in 11 cases (12.09\%), while, as mentioned above, there was also one patient presenting with acute dacryocystitis (1.10\%). In two cases (2.20\%) epiphora was the result of complications (secondary nasolacrimal duct obstruction due to scar formation) from previously performed functional endoscopic sinus surgery (FESS). In one patient (1.10\%) epiphora was caused by Wegener's granulomatosis involving the nasal mucosa. Main causes of epiphora are summarized in Table 2.

\section{Simultaneous treatment of additional pathology}

More often than not, no additional pathology was detected during the preoperative evaluation. However, in 19 patients (21.84\%), additional endonasal pathology was diagnosed and further intervention was indicated. During surgery, the additional intranasal intervention (namely, functional endoscopic sinus surgery, septoplasty, turbinoplasty) were carried out prior to DCR. The additional operations performed are summarized in Table 3.

Operative procedure

All patients were operated under general anaesthesia. De- 
Table 2. Causes of epiphora.

\begin{tabular}{|lc|}
\hline Cause & Cases (\%) \\
\hline Primary Acquired Nasolarimal Duct Obstruction & $62(68.13 \%)$ \\
\hline Lacrimal Sac Mucoceles & $14(15.38 \%)$ \\
\hline Chronic Dacryocystitis & $11(12.09 \%)$ \\
\hline Acute Dacryocystitis & $1(1.10 \%)$ \\
\hline Previous FESS Complications & $2(2.20 \%)$ \\
\hline Wegener's Granulomatosis & $1(1.10 \%)$
\end{tabular}

Table 3. Additional operations performed simultaneously with the DCR procedure.

\begin{tabular}{lc}
\hline Operation & Patients (\%) \\
\hline Functional Endoscopic Sinus Surgery (FESS) & $10(11.49 \%)$ \\
\hline Septoplasty & $2(2.30 \%)$ \\
\hline FESS and Septoplasty & $5(5.75 \%)$ \\
\hline Septoplasty and Turbinoplasty & $2(2.30 \%)$
\end{tabular}

congestion of the nasal mucosa was achieved using surface application of xylometazoline solution (0,1\%). Local anaesthesia and simultaneous vasoconstriction was performed using intramucosal injection of local anaesthetic ( $2 \%$ lidocaine) with 1:100.000 adrenaline solution. Catheterization of the lacrimal duct system was performed by an ophthalmologist with a light probe through -usually- the inferior lacrimal canaliculus.

The optical fibre was inserted in such a way as to transilluminate the lacrimal sac through the lateral nasal wall. The area of maximal illumination as seen from an endonasal point of view corresponds to the posterior (dorsal) part of the lacrimal sac, which is covered medially by a thin bony plate. This area is situated between $1 \mathrm{~mm}$ to $1 \mathrm{~cm}$ ventrally to the axilla of the middle turbinate.

Bone drilling at this area using a specialized endonasal straight drill with a diamond burr (no. 4, 5 or 6, according to available endonasal space) on an angled hand-piece followed, with formation of a round-shaped window $1 \mathrm{~cm}$ in diameter until the medial wall of the lacrimal sac was exposed. Next, a vertical incision of the medial wall of the lacrimal sac was made by use of a sickle knife. The greatest part of the medial wall of the lacrimal sac was removed using an angled, Castelnuovo-type (no. 3 or 4) cutting forceps. Bicanalicular intubation with a silicone stent was carried out by an ophthalmologist and the stent ends were knotted together endonasally.
In case of a protruding agger nasi cell, opening of the cell with a nasal forceps or intranasal drilling with a diamond burr is performed up until the point of the lateral wall.

In patients in whom the uncinate process is anterior in relation to the lacrimal sac, inferior uncinectomy between the vertical and horizontal part of the process is essential. Uncinectomy using an antrum punch follows. The landmark for this procedure is the inferior level of the ethmoidal bulla. The uncinate process is luxated medially and resected following its insertion in the lateral nasal wall.

In cases when septal deviation hinders the DCR procedure, septoplasty is conducted prior to DCR. If indicated, surgery to the head of the middle turbinate follows.

During endonasal DCR care should be taken not to place the osteotomy window too cranially so as to prevent development of the lacrimal sump syndrome ${ }^{(9)}$, a major cause of DCR failure. This syndrome occurs when the residual lacrimal sac forms a blind pouch where tears are collected. Recurrent dacryocystitis may follow. Therefore, removal of a large part of the medial wall of the lacrimal sac and softening of the lacrimal bone with a drill and a lame shaver is recommended. In our series, no patient developed the sump syndrome.

In six patients, in whom the uncinate process was inserted anteriorly to the ostium of the maxillary sinus an uncinectomy was also performed. In one patient, extensive pneumatisation of the agger nasi cells was detected. In this particular patient, the agger nasi cells were opened to achieve a better visualization. No nasal packing was used, except in cases where FESS was performed in addition. In these patients, a small pack would be placed and left in situ for one day.

\section{Post-operative care and monitoring}

Oral and topical antibiotics as well as steroid eye drops were initiated on the day of surgery and continued for five days. Patients underwent routine irrigation of the lacrimal duct system by an ophthalmologist once a week during the first month postoperatively, twice a month during the second month and once a month during the third month postoperatively. Endoscopic endonasal examination, to test for patency of the duct system, was performed as standard on days 15, 21 and 30 post-operatively. Mean post-operative silicone stents duration was 6.1 weeks (range 4 - 12 weeks). This was shorter in duration to the intended period of 3-months due to poor compliance secondary to discomfort. In addition, those patients who presented with complications complained of endonasal irritation necessitating stent removal less than 2 months postoperatively. Mean patient follow-up conducted on an outpatient basis was 17.3 months and ranged from 12 to 24 months. Follow-up consisted of routine endoscopic and ophthalmologic evaluation at every visit and included lacrimal irrigation, fluorescein dye disappearance test and Jones test I. 
Table 4. Results.

\begin{tabular}{lc|}
$\begin{array}{l}\text { Anatomical } \\
\text { Length of Follow up (months) }\end{array}$ & Patients (\%) \\
\hline Mean \pm SD & $17.2( \pm 3.8)$ \\
\hline Range & $12-24$ \\
\hline Time to stent removal (weeks) & \\
\hline Mean \pm SD & $6.1( \pm 1.3)$ \\
\hline Range & $4-10$ \\
\hline Success Rate & $95.60 \%$ \\
\hline Functional & $95.60 \%$ \\
\hline Anatomical & $95.60 \%$ \\
\hline Reasons of Failure (Cases) & 1 \\
\hline Inappropriate stent removal & 3 \\
\hline Granulation tissue formation &
\end{tabular}

Functional success was defined as symptomatic relief in tearing (epiphora), resulting in no further episodes of dacryocystitis and ability to irrigate the lacrimal system postoperatively. Anatomical success was achieved if there was a patent lateral nasal wall bone window on nasal endoscopy postoperatively and there was no obstruction to intranasal flow of saline during syringing via the lacrimal puncta.

\section{Results}

Post operative surgical success, at last follow-up, was present in $95.60 \%$ (87 out of 91) of cases. Functional and anatomical success rate were the same. Patients who underwent revision DCR were considered as unsuccessful cases. Only four patients failed to show any improvement after DCR. None of these four patients had bilateral nasolacrimal duct obstruction. Only one of these patients underwent an additional endonasal procedure at the time of DCR. The results are summarized in Table 4. One patient had an unsuccessful functional result, with complete lacrimal duct system obstruction due to inappropriate silicone stent removal postoperatively. Stent rests remained in the lacrimal sac area, causing localized granuloma formation. Revision surgery was performed and functional success was achieved three months postoperatively. In the three remaining patients, there was postoperative granulation tissue formation. Revision surgery under local anesthesia was performed consisting of granulation scar tissue excision without the use of stents. No major complications (i.e. complications involving the extraocular muscles or the optic nerve) were observed. No periorbital fat exposure was noted. Minor complications occurred in 6 out of 91 procedures ( $6.59 \%$ ); 2 patients developed acute dacryocystitis that was treated successfully with a 1-week course of topical and oral antibiotic therapy and 4 patients had periorbital ecchymosis that resolved spontaneously within 3 days postoperatively. No patient experienced significant postoperative nose bleeding.

\section{Discussion}

The external dacryocystorhinostomy approach had been the gold standard for many years. This is mostly due to the lack of appropriate equipment to support endonasal techniques. Early studies comparing the results between external and endoscopic DCR report significant difference between the two methods. Hartikainen et al. ${ }^{(10)}$ reported a primary success rate of $91 \%$ with the external approach, versus only a $75 \%$ success rate with the endoscopic approach. Of note the results after secondary surgery are comparable.

The advantages of DCR by means of an external approach include direct visualization of the lacrimal sac abnormalities and ease of suturing of the nasolacrimal sac and nasal mucosal flaps. Many authors argue that external DCR is technically less demanding than endonasal DCR.

The popularity of the endoscopic technique has been steadily increasing since it was first described. Since the introduction of modern operating equipment, such as the 45-degree angle endoscope, endonasal drills and other specialized endonasal instruments, the success rate is now comparable to that of external DCR and in some cases even superior ${ }^{(11,12)}$.

With superior visualization of the nasal cavity, nasal endoscopy helps evaluate the endonasal anatomy and detect with precision any nasal pathology, providing better information about the cause of the obstruction of the nasolacrimal duct system. In addition, having the ability of saccal transillumination, endoscopic vision provides us with direct control over the nasolacrimal area. Saccal transillumination is of great significance, because it helps to accurately and quickly identify the lacrimal sac without excessive drilling of the neighboring bone area. Through the endoscopic approach, any intranasal or paranasal pathological conditions may be simultaneously corrected. Moreover, the absence of a visible surgical scar is of great cosmetic benefit to the patient. Additionally, the possibility of disruption to the medial canthal ligaments and a disturbance of the pumping function of the orbicularis oculi muscle, which may complicate surgery by means of an external approach, are avoided.

Accuracy in preoperative localization of the area of the lacrimal system obstruction is very important to achieve a successful result with endoscopic DCR. Endoscopic DCR is indicated in patients with saccal and post-saccal obstruction but is not recommended in cases of pre-saccal obstruction. The lacrimal points and the lacrimal pathways should be patent to assess feasibility 
of endonasal DCR. Tears should be able to reach the lacrimal sac; therefore, saccal obstruction may be partial but not complete. DCR would not be an appropriate solution if complete obstruction is present. Therefore investigation of the lacrimal duct system and precise determination of the site of the obstruction preoperatively through fluorescein tests and dacryocystography are of major significance. An ophthalmologist probes the canaliculi with a Bowman capsule and if localization of the area of the lacrimal system obstruction is uncertain, dacryocystography and/or CT-dacryocystography is conducted. Every patient undergoes a CT scan evaluation. Anatomical information obtained through a CT scan is of vital importance when planning surgical management. Although a CT scan does not provide information about the localization of the obstruction, it provides information about the position of the lacrimal sac in regard to the lateral nasal wall and indicates the presence of additional endonasal and paranasal pathology. Additionally, a CT scan detects anatomical variations of the nasal cavity, such as the anatomical relation of the uncinate process to the frontal process of the maxillary or to the lacrimal bone, the presence of concha bullosa, the presence of an agger nasi cell or frontal cells and further anatomical information important for surgical management.

We do not recommend preservation of nasal mucosal flaps, because they are associated with postoperative fibrosis and obstruction and removal of mucosal flaps does not affect the success rate of the outcome ${ }^{(13,14)}$.

We do not routinely perform histological evaluation of the excised part of the medial lacrimal sac, because the incidence of neoplasia is very low (0.7\%). A lacrimal sac biopsy should be performed when there is suspicion of a neoplasm based on the clinical, historical, or intraoperative findings, rather than routine biopsy in all patients with nasolacrimal duct obstruction (15). There has been considerable disagreement over appropriate time of stent removal and even stent application. Some authors argue that stent removal earlier than 3 months postoperatively is often the cause of failure, because stent application maintains patency of the lacrimal system and prevents infections ${ }^{(16)}$. On the contrary, other authors recommend no silicone intubation at all, since it does not improve the surgical outcome ${ }^{(17,18)}$. The question of whether stents help, hinder or have no effect in DCR outcomes still remains unanswered ${ }^{(19)}$.

In our experience, signs of failure of surgery typically appear within the first 3 months. This is the reason why we recommend a minimum period of 3 months postoperatively when evaluating the outcome of DCR surgery. This is supported by other centres concluding that complications resulting in surgery failure occur within a 3 month period (20).

The results obtained with the endonasal approach with use of the drill for formation of the lateral nasal wall osteotomy in this series are comparable to those of the most successful series published to date in the literature ${ }^{(11,14,21,22)}$.

The relatively high success rates obtained in the present study may be due to the application of meticulous surgical technique with simultaneous treatment of any co-existing obstructing intranasal pathology (e.g. septal deviation) and prevention of synechiae building between the osteotomy site and the nasal septum and/or the lateral aspect of the middle turbinate. Use of the drill is particularly beneficial for bone removal at the area of the lateral nasal wall cranially to the insertion of the middle turbinate that covers medially the superior half of the lacrimal sac ${ }^{(21)}$. Furthermore, repeated meticulous irrigation of the duct system performed by an ophthalmologist during the first 3 months postoperatively should also be considered a major factor contributing to the observed functional and anatomical success in the present series. With repeated irrigation, the lacrimal sac remains clear and patent in cases of presence of mucous and blood remnants and synechiae. Of note, functional failure with no evidence of anatomical obstruction at the fistula site on postoperative nasal endoscopy may occur in as many as $51 \%$ of failed surgeries ${ }^{(12)}$.

\section{Conclusion}

Dacryocystorhinostomy by means of the endonasal approach with the use of the drill without creating mucosal flaps provides very favorable postoperative long-term results and therefore should be considered in all patients with saccal and postsaccal lacrimal sac obstruction.

\section{Acknowledgements}

The authors would like to acknowledge the valuable contribution of Mr. Paul Charlesworth in language editing of the present manuscript.

\section{Authorship contribution}

AS: Corresponding author, surgeon in charge

EE: Coauthor, surgeon in charge

HG: Coauthor

ET: Coauthor

KG: Coauthor

\section{Conflicts of Interest}

None

\section{References}

1. Kountakis SE. Encyclopedia of Otolaryngology, Head and Neck Surgery. Springer, 2013.
2. Toti A. Nuovo metodo conservatore di cura radicale delle suppurazioni croniche del sacco lacrimale (dacriocistorinostomia). Clin Mod Firenze 1904; 10: 385-387.
3. Dupuy-Dutemps L, Bourguet J. Procede plastique de dacryocystorhinostomie et ses resultats. Ann Ocul 1921; 158: 241-261.

4. Caldwell GW. Two new operations for 
obstruction of the nasal duct, with preservation of the canaliculi, and with an incidental description of a new lachrimal probe. Am J Opthalmol 1983; 10: 189-193.

5. West JM. A Window Resection of the Nasal Duct in Cases of Stenosis. T Am Ophthal Soc 1910; 12: 654-658.

6. Halle M. Zur intranasalen Operation am Traenensack. Arch Laryngol Rhinol 1914; 28: 256-266.

7. Saratziotis A, Emanuelli E, Gouveris $H$, Babighian G. Endoscopic dacryocystorhinostomy for acquired nasolacrimal duct obstruction: creating a window with a drill without use of mucosal flaps. Acta Otolaryngol 2009; 129: 992-995.

8. Eloy P, Poirrier AL, Nicoli T, Marlair C, Delahaut G, Leruth E, Rombaux P. Cystic dilation of the distal end of the nasolacrimal duct: underrated cause of epiphora in adults and its endoscopic treatment. Rhinology 2012; 50: 436-441.

9. Migliori ME. Endoscopic evaluation and management of the lacrimal sump syndrome. Opthal Plast Reconstr Surg 1997; 13: 281-284.

10. Hartikainen J, Antila J, Varpula M, Puukka P, Seppä H, Grénman R. Prospective Randomised Comparison of Endonasal Endoscopic Dacryocystorhinostomy and External Dacryocystorhinostomy. Laryngoscope 1998; 108: 1861-1866.

11. Leong SC, Macewen CJ, White PS. A systematic review of outcomes after dacryocystorhinostomy in adults. Am J Rhinol Allergy 2010; 24: 81-90
12. Simon Ben GJ, Joseph J, Lee S, Schwarcz RM, McCann JD, Goldberg RA. External versus endoscopic dacryocystorhinostomy for acquired nasolacrimal duct obstruction in a tertiary refferal center. Ophthalmology 2005; 112: 1463-1468

13. Kansu L, Aydin E, Avci S, Kal A, Gedik S. Comparison of surgical outcomes of endonasal dacryocystorhinostomy with or without mucosal flaps. Auris Nasus Larynx 2009: 36: 555-559.

14. Ramakrishnan VR, Hink EM, Durairaj VD, Kingdom TT. Outcomes after endoscopic dacryocystorhinostomy without mucosal flap preservation. Am J Rhinol 2007; 21 . 753-757.

15. Lee-Wing MW. Clinicopathologic analysis of 166 patients with primary acquired nasolacrimal duct obstruction. Ophthalmology 2001; 108: 2038-2040.

16. Muscatello L, Giudice M, Spriano G, Tondini L. Endoscopic dacryocystorhinostomy: personal experience. Acta Otorhinolaryngol Ital 2005; 25: 209-213.

17. Unlu HH, Gunhan K, Baser EF, Songu M. Long-term results in endoscopic dacryocystorhinostomy: is intubation really required? Otolaryngol Head Neck Surg 2009; 140: 589-595.

18. Smirnov $G$, Tuomilehto $H$, Teräsvirta $M$, Nuutinen J, Seppä J. Silicone tubing is not necessary after primary endoscopic dacryocystorhinostomy: a prospective randomized study. Am J Rhinol 2008; 22: 214-217.

19. Shah H. Comparison of surgical outcome in endoscopic dacryocystorhinostomy with and without silicone stent placement. Nat $J$ Med Res 2013; 3: 34-37.

20. Moore WM, Bentley CR, Olver JM. Functional and anatomic results after two types of endoscopic endonasal dacryocystorhinostomy: surgical and holmium laser. Ophthalmology 2002; 109: 1575-1582.

21. Tsirbas A, Wormald PJ. Endonasal dacryocystorhinostomy with mucosal flaps. Am $J$ Opthalmol 2003; 135: 76-83.

22. Vishwakarma R, Singh N, Ghosh R. A study of 272 cases of endoscopic dacryocystorhinostomy. Indian J Otolaryngol Head Neck Surg 2004; 56: 259-261.

Athanasios Saratziotis, MD Department of Otolaryngology Head and Neck Surgery University Hospital of Larissa Mezourlo

41110, Larissa

Greece

Tel: +30-693-213 6055

Fax: +30-241-067 0248

Email: athanasios_saratziotis@yahoo. it 